\title{
Article
}

\section{Caring for women making unconventional birth choices: A meta-ethnography exploring the views, attitudes, and experiences of midwives}

Feeley, Claire Lauren, Thomson, Gillian and Downe, Soo

Available at http://clok.uclan.ac.uk/26077/

Feeley, Claire Lauren ORCID: 0000-0002-8013-0352, Thomson, Gillian ORCID: 0000-0003-3392-8182 and Downe, Soo ORCID: 0000-0003-2848-2550 (2019) Caring for women making unconventional birth choices: A meta-ethnography exploring the views, attitudes, and experiences of midwives. Midwifery, 72 . pp. 50-59. ISSN 0266-6138

It is advisable to refer to the publisher's version if you intend to cite from the work. http://dx.doi.org/10.1016/j.midw.2019.02.009

For more information about UCLan's research in this area go to http://www.uclan.ac.uk/researchgroups/ and search for <name of research Group>.

For information about Research generally at UCLan please go to http://www.uclan.ac.uk/research/

All outputs in CLoK are protected by Intellectual Property Rights law, including Copyright law. Copyright, IPR and Moral Rights for the works on this site are retained by the individual authors and/or other copyright owners. Terms and conditions for use of this material are defined in the policies page. 


\section{Accepted Manuscript}

Caring for women making unconventional birth choices: A meta-ethnography exploring the views, attitudes, and experiences of midwives.

Claire Feeley, Gill Thomson, Soo Downe

PII:

DOI:

Reference:

To appear in:

Received date:

Revised date:

Accepted date:
S0266-6138(19)30040-3

https://doi.org/10.1016/j.midw.2019.02.009

YMIDW 2424

\section{Midwifiery}

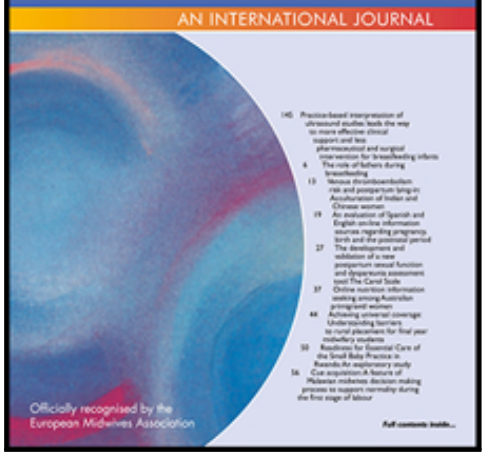

Please cite this article as: Claire Feeley, Gill Thomson, Soo Downe, Caring for women making unconventional birth choices: A meta-ethnography exploring the views, attitudes, and experiences of midwives., Midwifery (2019), doi: https://doi.org/10.1016/j.midw.2019.02.009

This is a PDF file of an unedited manuscript that has been accepted for publication. As a service to our customers we are providing this early version of the manuscript. The manuscript will undergo copyediting, typesetting, and review of the resulting proof before it is published in its final form. Please note that during the production process errors may be discovered which could affect the content, and all legal disclaimers that apply to the journal pertain. 


\section{Highlights}

- Available research suggests midwives can be willingly facilitative or reluctantly accepting of women's unconventional birth choices.

- Differing attitudes were informed by differing values towards women's autonomy.

- Some midwives faced vulnerabilities associated with fear of reprisals or litigation.

- Self-employed midwives appeared to be more likely to be willingly facilitative.

- All midwives reported that relationships with women were central to their care. 


\section{Title page}

Caring for women making unconventional birth choices: A meta-ethnography exploring the views, attitudes, and experiences of midwives.

\section{Authors}

1. Claire Feeley MSc, BSc, RM [corresponding author]

University of Central Lancashire, Preston, Lancs, UK

Postal address: 91 Felsted, Caldecotte, Milton Keynes, MK7 8FD

clfeeley@uclan.ac.uk

2. Dr Gill Thomson, PhD, MSc, BSc, FHEA

University of Central Lancashire, Preston, Lancs, UK

GThomson@uclan.ac.uk

3. Prof. Soo Downe, $\mathrm{PhD}, \mathrm{MSc}, \mathrm{BSc}$

University of Central Lancashire, Preston, Lancs, UK

SDowne@uclan.ac.uk

1. Conflict of interest: None declared

2. Ethical approval: Not applicable

3. Funding sources: This work has been carried out as part of Claire Feeley's PhD studentship at the University of Central Lancashire. 


\section{Introduction}

There is a global movement towards improved human rights during childbirth (World Health Organisation, 2012). Respect for women's decision-making, autonomy, including the right to decline recommended care or treatment is central to the movement (The White Ribbon Alliance, 2013). However, in reality, women's birț choices can be bound in ethical dilemmas, moralistic opposition and restrictive care provision (Dahlen, Jackson, \& Stevens, 2011; Keedle, Schmeid, Burns, \& Dahlen, 2015; Viisainen, 2000); some women face opposition when attempting to exert their agency (The White Ribbon Alliance, 2013; World Health Organisation, 2012), particularly those deemed 'unconventional' (Keedle et al., 2015; Shallow, 2013; Viisainen, 2000). Broadly, unconventional birth choices can be characterised by those that fall outside of national clinical guidelines. These can include choices for more technical care than is recommended (for instance elective cesarean section or early labour induction with no medical indication). However, in highly technical, risk-averse maternity systems that are prevalent in most high income settings, choices for less medical intervention than is recommended are more likely to be deemed unconventional. These may include women who have medical or obstetric risk-factors seeking midwife-led care settings (home or birth centres), or women declining recommendations for specific treatments or interventions, such as routine ultrasound scanning, or labour induction after 41 weeks gestation. For the purposes of this review, we have chosen to focus on birth choices related to less medical intervention. 
Midwives, like other maternity care professionals, work within contexts where medico-legal and medico-ethical tensions around caring for a mother-baby dyad are prevalent (Deshpande \& Oxford, 2012; Dexter, Windsor, \& Watkinson, 2013). These debates include conceptualizations of risk (Symon, 2006), the under or overmedicalization of childbirth (recently reframed as 'Too much, too soon, too little, too late') (Renfrew et al., 2014) and paternalistic cultures vs self-determination (Edwards, Murphy-Lawless, Kirkham, \& Davies, 2011). These debates also sit alongside evidencebased medicine (EBM). EBM has the intended goal of applying the best available scientific evidence to healthcare practices or treatments, in the context of patient values and clinical skills and expertise (Greenhalgh, 2014). However, EBM has been criticized when it is used to justify the application of formulaic, population-based hospital policies and guidelines to specific individuals (Kotaska, 2011). From the perspective of maternity care, it has been argued that guidelines have been reified into rules, defendable in court should the situation arise, irrespective of the needs and choices of individual women and babies (Downe, 2010). In this context, conflicts have arisen between the rhetoric of women's birth choices, and the organizational obligations of professionals providing the care (Kotaska, 2011; Kotaska, 2017; Kruske, Young, Jenkinson, \& Catchlove, 2013).

There is a body of research on women's experiences of unconventional birth choices, including freebirthing (Feeley \& Thomson, 2016); vaginal birth after caesarean (VBAC) at home (Keedle et al., 2015) or in a birth pool (McKenna \& Symon, 2014), and twin births or breech births at home or in a birth center (Holton \& de Miranda, 2016; Jackson, Dahlen, \& Schmeid, 2012). However, to date, little is known about the views and experiences of midwives caring for women making such choices. The aim of this 
review was, therefore, to gather, quality assess, synthesize and interpret the views, attitudes, and experiences of the midwives caring for women making unconventional birth choices where those choices were associated with less medical interventions.

\section{Methods}

Research design

A systematic search and meta-ethnography informed by Noblit and Hare (1988) and Schutz (1962) was undertaken. Meta-ethnography was chosen due to its capacity to explore a range of qualitative studies focusing on a particular phenomenon and to formulate new conceptualizations of a phenomenon (Atkins et al., 2008). Noblit and Hare (1988) provide a seven-phase approach to selecting, appraising, summarising, interpreting and synthesizing qualitative studies, see Figure 1. A review protocol for this study was submitted to PROSPERO (The International Prospective Register of Systematic Reviews), registration number CRD (blinded for review). Additionally, the study has been written in adherence with Enhancing transparency in reporting the synthesis of qualitative research (ENTREQ) (Tong, Flemming, McInnes, Oliver, \& Craig, 2012).

Figure 1 Noblit and Hare's Seven Phase Approach

Reflexivity

To enhance the trustworthiness of the review (Lincoln \& Guba, 1985; Walsh \& Downe, 2006), all authors reflexively considered their prior beliefs before commencing the study. In summary, X (blinded for review) and X are midwives and X has a background in psychology. All have a firm philosophy of woman-centered care and believe it is crucial to support and facilitate childbearing women in decision making even if these 
decisions fall outside of standard protocols and guidelines, or outside of the personal beliefs and values of the authors. $\mathrm{X}$ and $\mathrm{X}$ also have experience of the personal anxiety and tensions that arises when trying to support women in this situation, of the risk of over-identifying either with the organizational culture, or with the woman's particular situation.

\section{Search strategy and selection criteria}

A pre-designed comprehensive search strategy was carried out to seek all available studies. Free text search terms were developed using 'Population and their Problems, Exposure and Outcomes or Themes' (PEO) framework (Bettany-Saltikov, 2012). Additionally, the search terms were reviewed by two librarians given the complexity of the review. A pilot test was carried out to ensure the search strategy was fit for purpose. The search was carried out during August-September 2016 (updated in October 2017) using pre-developed search terms: midwi* OR nurse-midwi ${ }^{\star}$ AND facilita* OR attitud ${ }^{*}$ OR view* OR experienc ${ }^{*}$ OR belief* OR perception* OR opinion* OR perspective* OR support or car ${ }^{*}$ AND birth OR delivery OR birth choice OR vaginal birth after cesarean OR VBAC OR breech OR home OR birth centre. Eight international bibliographic databases were searched: Cumulative Index of Nursing and Allied Health Literature (CINAHL), MEDLINE, Maternity and Infant Care, MIDIRS, PsychINFO, Lilacs, African Journals Online (AJOL) and Web of Science. Additional searches were carried out using reference chasing, citation chasing, author tracking, hand searching midwifery journals, unpublished thesis database Ethos, and professional networks. The full search strategy can be found in the supplementary file 1. The inclusion/exclusion criteria were predesigned, detailed in Table 1. Studies before the publication of the 1993 UK 'Changing Childbirth' report (DH, 1993) were 
excluded as this period marked a change in concurrent international discourses (Sandall, Bourgeault, Meiger, \& Schuecking, 20o1) surrounding childbirth, where a greater emphasis was placed upon women's right to choice and control.

\section{Table 1 inclusion/exclusion criteria}

\section{Screening and Quality appraisal}

Initial screening was carried out by title and abstract by the first author. All papers that met the initial screening criteria were obtained in full. The fufl texts were scrutinized by two authors independently, and then inclusion was agreed by consensus. Debates regarding the value of quality assessments for qualitative syntheses, mirrors the same debate for primary qualitative research (Atkins et al., 2008; France et al., 2014). The debate largely centers around whether or not there is a philosophical rationale for undertaking quality assessments (Sandelowski, Docherty, \& Emden, 1996; Campbell et al., 2011), and if so, what criteria should be used (Thomas \& Harden, 2008; Campbell et al., 2011). Our view aligns with those who recognise the increasing value and contribution of qualitative studies to evidence based policy and practice, signifying an emerging need to ensure minimal standards are met (Walsh \& Downe, 2006; Thomas \& Harden, 2008; Campbell et al., 2011). In this study the quality of the included papers was assessed by two authors using the same process of independent assessment followed by consensus agreement, using the Walsh \& Downe (2009) integrated quality appraisal tool. The tool assesses the: scope and purpose; design, sampling strategy, analysis, interpretation, reflexivity, ethical dimensions, relevance, and transferability. Each paper was also graded on a scale of A to D to 
provide an overall assessment of the quality (Downe et al., 2009), with a full exposition of the grading framework provided in Supplementary File 2.

\section{Synthesis}

Initial data extraction comprised of identifying and tabulating each studies' key characteristics i.e. their assigned code, author, country, aims, theoretical perspective, sample, setting, data collection method, data analysis method, adherence to ethics, reflexivity discussion, key findings and the quality grade. The synthesis method combined the inductive meta-ethnography approach of Noblit and Hare (1988) and Schutz (1962) and included several readings of each study, translation, and synthesis. As per Noblit and Hare (1998), meta-ethnography operates on the conceptual level, whereby, the familiarisation stage involved each paper being read individually to identify any author constructs, themes and metaphors. All key concepts were recorded, assigned a code that captured the meaning of the concept, and tabulated using a tool developed by Downe et al., (2009). Quotes from participants were used to illustrate the identified concepts.

The coded concepts from the studies formed the basis of 'first order constructs' (Campbell et al., 2011). It is noted that Noblit and Hare (1988) did not originally refer to the use of constructs, nor have they updated their seminal text. However, methodology within meta-ethnography has grown in the 29 years since its inception (France et al., 2015). The use of constructs emerged primarily from Schutz's (1962) concepts of first, second and third order constructs and have been frequently used in meta-ethnographies (France et al., 2014). Therefore, we felt it was justifiable to combine constructs with our meta-ethnographic approach. 
In this study, first-order constructs were captured as the initial concepts identified in the familiarisation stage. Second order constructs were produced from the constant comparison approach as per Noblit and Hare (1988). This approach aims to identify how the studies relate to each other; similarities are known as 'reciprocal translation', dissimilarities are known as 'refutational translation'. Where the studies generate simultaneous reciprocal and refutational translations, a researcher may develop a 'line of argument' which is a new conceptualisation that encompasses both (Noblit \& Hare, 1988). This study generated both reciprocal and refutational second order constructs, that were further synthesised into core themes at a higher level of interpretation, captured as 'third order constructs'. Additionally, a tentative 'line of argument' was developed to capture the similarities and dissimilarities across the data set. All key themes and interpretations were carried out over several iterations, moving back and forth from the primary data to the emerging themes. Extensive discussions and feedback with all three authors ensured the findings adequately represented the data. The full data set is provided in Supplementary file 3.

\section{Results}

Twelve of 7,237 papers met the inclusion criteria at the abstract stage, see Figure 1. Five were excluded at the full-text stage; two were quantitative studies (Danerek et al., 2011; Jenkinson et al., 2015), one was an audit (Sellar, 2008), one a case study with little focus on midwifery care (Jankowski \& Burcher, 2015) and one was a study that focused maternal request for elective caesarean (Karlström, Engström-Olofsson, Nysted, \& Thomas, 2009). Three papers reported findings from the same study (Wickham, 2009; Wickham, 2010; Wickham, 2011), therefore the total number of 
included studies was five, across seven papers (Cobell, 2015; Jenkinson et al., 2016; Symon, Winter, Donnan, \& Kirkham, 2010; Thompson, 2013; Wickham, 2009; Wickham, 2010; Wickham, 2011). One study that was included was an unpublished primary qualitative study, that met the inclusion criteria (Cobell, 2015). All were graded ' $\mathrm{C}$ ' or above through the quality appraisal process. An updated search in October 2017 found one further paper (Jenkinson, Kruske, \& Kildea, 2017). As this was a secondary analysis of a study already included in the review (Jenkinson et al., 2016), it was excluded. Study characteristics and quality grading are presented in Table 2. The included studies were of heterogeneous research designs and were undertaken in the UK (3), Australia (1), and in multiple settings (1; UK, US, and New Zealand), and included 55 midwives in total. Notably, all studies were undertaken in high-income countries, all with state-funded health care systems, and where midwives are the lead professionals for healthy childbearing women at low risk of complications. However, one study (Symon et al., 2010) had a different focus to the other included studies as it concerned independent midwives' experiences of poor neonatal outcomes following women's unconventional birth choices.

Figure 2 PRISMA flow chart

Table 2 Study Characteristics

\section{Findings}

The first, second and third order constructs are presented in Table 3. In the following sections, the three third order constructs are discussed, together with exemplar quotes from the included studies. Quotes include a key to identify whether the midwives were self-employed (SEM) or employed by institutions (EM). 
Table 3 Constructs

\section{Perceptions of women's decision-making}

This construct conveys the midwives' perceptions of the women making unconventional birth choices, and conflicting views regarding the maternal-fetal dyad.

The 'type' of woman

Participants across three of the studies perceived women who opted for unconventional birth choices to be a certain 'type' of person (Cobell, 2015; Symon et al., 2010; Thompson, 2013). Participants in these studies associated the desire for control with well-educated women who wanted fewer interventions during birth (Cobell, 2015; Symon et al., 2010; Thompson, 2013). The participant's in the Cobell study (2015, p.39) reported that the women making these choices were predominantly 'Caucasian', and 'independent'. These characteristics concurred with the participants in the Thompson (2013, p.568) study, who reported characteristics such as women being 'well-educated' and 'intelligent' as associated with making unconventional birth choices. These attributes were viewed positively (Cobell, 2015; Symon et al., 2010) or negatively (Thompson, 2013). Self-employed UK independent midwives were positive about women taking responsibility for their decisions regardless of the outcome:

'And I know, working with the women I've worked with, that the vast majority of those women - with positive and negative outcomes-are very clear that they would rather have gone that route of taking that decision themselves with the best information available to them and to move forward with that.' (Participant SEM, (Symon et al.,

$$
\text { 2010), p.282). }
$$


Avoiding intervention, avoiding repeated trauma

Some participants noted that a previous traumatic experience could influence women's unconventional choices (Cobell, 2015; Symon et al., 2010). One participant (employed midwife) in the study by Cobell (Cobell, 2015) suggested that a previous birth involving multiple interventions had influenced a woman's decision to opt for a subsequent birth outside of recommended guidelines:

'I think it was more that she didn't want that medical, bright lights, legs up in the air, kind of scenario' (Beth EM, (Cobell, 2015), p.40).

Independent midwives in the UK (Symon et al., 2010), reported that women sought their services (usually homebirths) to avoid a repetition of 'traumatic NHS care' (p.283), even when experiencing multiple and concurrent risk factors, such having had a previous cesarean, or having either twins or a breech presentation in the current pregnancy (Symon et al., 2010). Further examples in this study included women declining emergency transfers to avoid NHS care (Symon et al., 2010):

'What is really hard to balance is the women who are so frightened of NHS care or going into hospital that they put themselves into really complex situations based on fear.' (Participant SEM, (Symon et al., 2010), p. 283).

\section{Conflicting views of maternal autonomy}

Participants across the studies acknowledged that, in principle, women had the right to make their own birthing decisions, including going against clinical advice or standard guidelines. In three studies, midwives expressed an explicit commitment to women's autonomy (Jenkinson et al., 2016; Symon et al., 2010; Wickham, 2010): 
'All you have to do is impart the recommended information. . . and at the end of the day.

.. it's the woman's choice to make that decision. .. It's a woman's right to choose. To choose care, and to refuse care and not to be punished for that.' (MW11 EM, (Jenkinson et al., 2016),p.5).

However, in specific situations, views about and attitudes towards maternal autonomy were conflicted. For example, some employed midwives in the UK (Thompson, 2013) expressed concern that the woman's choices might not be in the best interest of their fetus. This is a complex area, especially as, in UK law, the fetus is not recognized as having any rights independent of the mother. One midwife felt more secure once the baby was born, as it meant she could regain professional control over its wellbeing:

'The only rights we have are when the baby is actually born. You can then step in and give appropriate care. There is nothing we can do for the woman that refuses. We can, however, make sure the baby is safe. '(Participant EM,(Thompson, 2013), p.576).

The juxtaposition between maternal and fetal wellbeing was starkly illustrated in the study of self-employed midwives by Symon et al., (2010) in the context of neonatal deaths. Despite the emotional distress midwives felt when women declined transfer to hospital for fetal problems, they continued to provide supportive care, in recognition of womens right to autonomous decision making:

It is possible that if she had had an elective section she would have had two live babies, but there is no way she would have consented to an elective cesarean:(Participant, SEM, (38), p.284)

\section{Conflicting tensions as caregivers}


This third-order construct details the different sources of fears and frustrations experienced by respondents.

Fears and vulnerabilities

In three studies, employed midwives reported professional and medico-legal tensions, together with personal stress and vulnerabilities when women declined recommended care (Cobell, 2015; Jenkinson et al., 2016; Thompson, 2013). Issues related to fears of poor fetal or maternal outcomes, coupled with fears of being held accountable for care that women declined:

'I felt vulnerable (pause) I felt that I was being torn in two ways. In that, I had a duty of care to support her in her decisions but I also had a duty of care to keep her safe and she did understand all the risks. So it was difficult at the time.' (Participant EM, (Thompson, 2013) p.568).

Additional issues related to the impact of adverse outcomes on employed midwives' career (Jenkinson et al., 2016; Thompson, 2013). For some, this related to insurance issues when practicing outside of guidelines:

'If anything happens [poor maternal or fetal outcome] and I'm working outside of [hospital policies ... then I am not covered by vicarious liability. So then, there goes my house!' (MW4 EM, (Jenkinson et al., 2016), p.5).

High levels of stress associated with these concerns affected some participants more acutely than others. Thompson (Thompson, 2013) reported that employed midwives disclosed feeling out of their comfort zones, and frustration towards some women's requests. These requests were at times considered 'silly, 'challenging and tricky' 
(p.566) as well as time-consuming, to the detriment of other women's care. In contrast, employed midwives in the Cobell (Cobell, 2015) study reported vulnerabilities associated with feeling judged by their 'fearful' colleagues and that they 'had to prove themselves' as highly capable midwives (p.44), rather than being supported in their practice:

'I think I get the sense that sometimes midwives think it is going to go wrong.' (Kate EM, (Cobell, 2015), p.44).

The constraints of arbitrary restrictions

Some midwives reported entirely different sources of frustration (Cobell, 2015) and anger (Wickham, 2010). In Cobell's study (2015), some employed midwives considered rigid adherence to guidelines to be problematic, due to creating unnecessary fears when faced with requests for alternative choices:

'what we're doing is putting people into categories and institutionalizing them via our guidelines and making people afraid if you come out of guidelines' (Ava EM, (Cobell, 2015), p.45).

These midwives challenged the concept of guidelines as rules to follow, rather than their intended use as tools to inform clinical care in conjunction with women's wishes:

'It is a guideline, it's not law, it's not gospel' (Beth EM, (Cobell, 2015), p.45).

All of the independent midwives in Wickham's (2010) study remonstrated against strict definitions of term and post-term pregnancy. They argued that the parameters set by formal guidelines were 'arbitrary' (34, p.467), not based on robust clinical research, and counter to their experiences as midwives. They considered that the 
'pervasive pressure to accept medical interventions' (34, p.465) led to women being 'broken by the system' (33, p.2); a metaphor used to represent morbidities associated with routine and medicalized inductions:

'I just see the morbidity that's attached to that [induction for post-term pregnancy] and it breaks my heart. All those primips with their syntocinon drip in one arm and their sore fannies from all the prodding and they're on the monitor 'cause there's that whole package that goes with it ... it breaks my heart'. (Kate SEM, (Wickham, 2010), p.2) Managing the tensions

For employed midwives, a primary method of managing stress associated with medico-legal concerns was scrupulous documentation (Cobell, 2015; Jenkinson et al., 2016; Thompson, 2013); to demonstrate that appropríate care was provided in accordance with the woman's wishes, thereby providing them with a 'safety net' (36, p.567) and a source of 'protection' (38, p.9). The focus of Jenkinson's (2016) study was the implementation of a structured maternity care plan (MCP) to ameliorate the stress and fears of midwives consequent on women seeking out of guidelines care. Midwives reported feeling less stress when a woman had an MCP in place, and especially when more senior staff held overall responsibility for the MCP:

'I guess practitioners, midwives particularly, just relax a little bit more if a senior doctor has ppoken to her about the risks. . That's probably the. . advantage of them [MCPs].' (MW8 EM, (Jenkinson et al., 2016), p.6). 
Similarly, the employed midwives in Thompson's (36, p.568) study were more 'confident' and 'reassured' when a woman's birth plan had been endorsed by a senior midwife.

\section{Ways of working with-woman}

This third-order construct describes how midwives forged and maintained mothermidwife relationships to ensure that women remained engaged with health care services.

Relationships central to caregiving

For independent midwives in the Symon et al (Symon et al., 2010) study, the relational aspect of care was expressed by participants as 'being on their side' (p.282); this was considered to be of fundamental importance for deeply complex and challenging cases such as fetal death. For example, one self-employed midwife expressed:

'Half of me feels that if I'd turned into a different sort of person and bullied her into hospital, then that might have been the right thing to do as per keeping the baby alive. However, the other side of me was - I was the only person on her side... if I had bullied her into hospital and the baby died anyway, who would she have had on her side?' (Participant SEM, (Symon et al., 2010), p.282).

Employed midwives working within institutions (where continuity of carer was less likely) also felt that establishing rapport with women was essential in creating and maintaining positive midwife-woman relationships and for negotiating safe care plans (36, p.567). However, for some this was more difficult without an earlier relationship with the woman: 
'it's harder sometimes when you've not got that relationship with the woman but speaking personally for me, it's really important that we facilitate choice and ensure that she gets the positive response that she should get when she comes into the unit. So that's why I'm happy to do it' (Grace EM, (Cobell, 2015), p.109).

Some midwives also expressed personal benefits when caring for women who opt for unconventional birth choices:

'I feel privileged to look after women that have these plans and I get an overwhelming sense of achievement for them and I feel like it does really enhange how they feel positively.' (Kate EM, (Cobell, 2015), p.41).

Keeping women engaged in care provision

Honoring women's requests was also motivated by keeping women engaged in care (Cobell, 2015; Symon et al., 2010; Thompson, 2013; Wickham, 2010). For example, one midwife reported negotiating place of birth as a compromise between women's choices and perceptions of safety:

'I think some of them are encouraged to avoid home birth if they're very risky and that's a compromise being on the MLU [Midwife led unit].' (Mia EM, (Cobell, 2015), p.47) Concerns were raised that if staff were unwilling to negotiate a suitable and acceptable birth plan, then women may withdraw from the service (37, p.47) and/or opt to freebirth (without any health care assistance) (Jenkinson et al., 2016; Symon et al., 2010).

\section{Line of argument synthesis}

Whilst only five studies were found and included, the findings generated both 
'reciprocal' and 'refutational' data (Noblit \& Hare, 1988). Therefore, a tentative line of argument was developed to draw together salient points of similarity and differences across the data set. We acknowledge that further research is needed to strengthen the line of argument, however, it does provide important insights for further investigation:

The findings suggested that the midwives in the included studies, which encompassed both employed and independent midwives' appeared to be situated upon a spectrum of willingly facilitative or reluctantly accepting of women's unconventional birth choices. This seemed to be informed by the degree to which they value women's autonomy over institutional norms and fetal rights. However, their positioning was also influenced by vulnerabilities associated with professional accountability, subsequent litigation, and actual or potential reprisals arising from adverse events. Such vulnerabilities, and the adverse emotional consequences of them were particularly apparent for those working within institutions when compared to those working independently. However, for all midwives, the quality and nature of midwives' relationships with women were central to their response to, and management of, unconventional birth choices.

\section{Discussion}

Only five studies were located relating to the review question, indicating a paucity of research in this area. Therefore, whilst the findings need to be treated cautiously, some important insights were identified. The findings highlight a spectrum of views, attitudes, and experiences of midwives caring for women who choose unconventional birth options. Differences in opinions regarding women's autonomy, the degree to which women can be trusted to prioritize the wellbeing of their fetus, and the acceptability of women making counter-cultural choices were identified. These differences were contextualized by fears of accountability in the event of an adverse 
outcome, and the potential for subsequent litigation. Such concerns were primarily expressed by participants working within institutions. In contrast, independent midwives who had direct experience of caring for women who had adverse outcomes after declining emergency care, demonstrated strong commitments to maternal autonomy, expressed as 'being on their side', with little emphasis reported regarding litigious concerns. While the findings from the self-employed midwives are unsurprising, and also reflect the relational components of continuity of carer, the divergent values demonstrated by employed midwives require closer examination.

While the transferability of the review findings should be treated with caution, the issues reflect wider literature relating maternity professionals' views and experiences of medico-legal and medico-ethical tensions (Deshpande \& Oxford, 2012), perceptions of risk (Dexter et al., 2013), and perceptions of maternal autonomy (Kruske et al., 2013). This study suggests that employed midwives in high-income settings can experience difficult negotiations and institutional and social imperatives to follow populationbased guidelines, whilst simultaneously working with individual women who are making alternative decisions. Fear of litigation, workplace reprisals and loss of career consequent on working 'outside of the guidelines' is an unintended consequence of conflating guidelines with 'rules' for workers to follow (Downe, 2010). This is especially true if health workers protect themselves from negative emotional, legal, and financial sequelae by prioritizing adherence to guidelines over individually relevant care, and over women's' rights to personal autonomy. Critics suggest that the authoritative nature of guidelines has led to a shift away from an individualized care rhetoric, and towards a situation where any deviation from standard(ized) care has to be justified (Griffiths, 2009; Kotaska, 2011). Kotaska (2011) calls this 'guideline- 
centered care', which is in direct opposition to respecting women's autonomous decision making (Griffiths, 2009; Upshur, 2014). Inconsistencies across international and national guidelines (Weisz et al., 2007; Glantz, 2012), and even between neighboring hospitals (Hunter, 2004) also undermine ethical or moral arguments that the universal application of guidelines is best practice.

Our findings also support data from two other studies of employed midwives, that found coexistence of diverse values and perspectives within their midwifery cohorts (Thompson, 2003; Hunter, 2004). Thompson (2003) explored women's and midwives' narratives in relation to ethical components of receiving and providing care during labour and found that midwives were perceived as either 'procedure-oriented' or 'withwoman oriented' (p.596). She argued that midwifery care was informed by midwives ethical positioning. Hunter (2004) explored midwives' accounts of the 'emotional labor' of caring for women and established that two coexisting and conflicting ideologies of midwifery existed between midwives; 'with-woman' and 'with-institution' (p.261). Both studies broadly illustrate two extremes. One is based on a 'womancentered' philosophy, where the holistic needs of the woman guide the care provided and autonomous decision making is actively supported (The White Ribbon Alliance, 2013). This is opposed to a task-oriented approach or a 'guideline-centered' philosophy, in which the needs of the organization are prioritized over the needs of the individual woman (Griffiths, 2009; Kotaska, 2011). We suggest that midwives who are 'willingly facilitative' of women's unconventional birth choices, as our findings reveal, are closely aligned with a 'with-woman' ethical and ideological philosophy of care. In contrast, the 'reluctantly accepting' midwives appear to be more aligned with a task-oriented approach informed primarily by adherence to guidelines. 
Woman-centred care is central to the protected title of the midwife, that also includes autonomous practice and advocacy (International Confederation of Midwives, 2014). As such, our findings alongside Thompson (2003) and Hunter (2004), highlighting polarized midwifery values which raises issues with the midwifery project to be 'withwoman' and challenges the constructs of midwifery practice. Notwithstanding the organizational and institutional constraints of employed midwifery practice, already discussed, the divergence of values is of concern. For example, our findings demonstrated that some midwives resisted their autonomous professional status, preferring to defer and rely upon the input of senior midwives and/or medics. Arguably, reinforcing the hierarchal status quo (Pollard, 2011) and deferring personal responsibility. The wider literature has found women can feel coerced and steered into decision-making by maternity professionals in order to comply with local guidelines (Kruske et al., 2013; Shallow, 2013), Our findings highlight the tensions within midwifery practice which may contribute to women's experiences.

With all search strategies there is a risk of missing pertinent studies, however, we demonstrated a comprehensive systematic and rigorous strategy that included eight international bibliographic databases and seven additional search techniques to overcome search limitations. However, only five studies (7 papers) met the inclusion criteria and no studies were found in low or middle-income countries. The international scope of the review indicates that the findings may be applicable in other high-income countries where midwives are a strategic part of the workforce.

Conducting a meta-ethnographic synthesis is an interpretative process, but the risk of over or under interpretation of the data was minimized through author reflexivity to ensure that personal beliefs and values did not obscure important data within the 
included studies, and through rigor in study selection and analysis. The paucity of literature necessitates further research into this area of midwifery practice, and into the broader question of out of guidelines health care.

\section{Conclusion}

Despite strong international rhetoric in support of women's birth autonomy, midwifery practices around facilitation or restriction of maternal rights in this area remain contested. As the 'front window' of the maternity care team, and especially where women have chosen midwife-led care, midwives' decision making is critical to ensuring the optimal wellbeing of the mother and the baby when women make unconventional decisions. However, the findings of this review suggest that midwives' views in this area are situated along a spectrum, and are influenced by context as well as prior philosophies and values. To ensure the best quality of care and optimal outcomes when women make unconventional choices, it is essential to understand the nature and implications of different responses from midwives, and from other members of the health care team, including obstetricians and neonatologists. Future work in this area should encompass all of these perspectives.

\section{Word count: 5269}

\section{References}

Atkins, S., Lewin, S., Smith, H., Engel, M., Fretheim, A., \& Volmink, J. (20o8).

Conducting a meta-ethnography of qualitative literature: Lessons learnt. BMC Medical Research Methodology, 8(21)

Bettany-Saltikov, J. (2012). How to do a systematic literature review in nursing: A stepby-step guide (1st ed.). Maidenhead: Open University Press. 
Campbell, R., Pound, P., Morgan, M., Daker-White, G, B., N, Pill, R., Donovan, J. (2011). Evaluating meta-ethnography: Systematic analysis and synthesis of qualitative research. Health Technology Assessment, 15(43)

Cobell, A. (2015). What are midwives' experiences of looking after women in labour outside of trust guidelines? Unpublished manuscript.

Dahlen, H., Jackson, M., \& Stevens, J. (2011). Homebirth, freebirth, and doulas:

Casualty and consequence of a broken maternity care system. Women and Birth, 24, 47-50.

Danerek, M., Maršál, K., Cuttini, M., Lingman, G., Nilstun, T., \& Dykes, A. (2011). Attitudes of midwives in Sweden toward a woman's refusal of an emergency cesarean section or a cesarean section on request. Birth: Issues in Perinatal Care, 38(1), 71-79. doi:10.1111/j.1523-536X.2010.00440.X

Deshpande, N., \& Oxford, C. (2012). Management of pregnant patients who refuse medically indicated cesarean delivery. Reviews in Obstetrics and Gynecology, 5(3-4), e144-e15o.

Dexter, S., Windsor, S., \& Watkinson, S. (2013). Meeting the challenge of maternal choice in mode of delivery with vaginal birth after caesarean section: A medical, legal and ethical commentary. BJOG: An International Journal of Obstetrics \& Gynaecology, $121(2), 133-140$.

DH. (1993). Changing childbirth. London: Department of Health.

Downe, S. (2010). Beyond evidence-based medicine: Complexity and stories of maternity care. Journal of Evaluation in Clinical Practice, 16, 232-237. 
Downe, S., Walsh, D., Simpson, L., \& Steen, M. (2009). Template for metasynthesis. sdowne@uclan.ac.uk:

Edwards, N., Murphy-Lawless, J., Kirkham, M., \& Davies, S. (2011). Attacks on midwives, attacks on women's choices. Association for Improvements in the Maternity Services, 23(3)

Feeley, C., \& Thomson, G. (2016). Tensions and conflicts in 'choice'. women's experiences of freebirthing in the UK. Midwifery, 41, 16-21.

France, E., Ring, N., Thomas, R., Noyes, J., Maxwell, M., \& Jepson, R. (2014). A methodological systematic review of what's wrong with meta-ethnography reporting. BMC Medical Research Methodology, 14(119)

Glantz, J. (2012). Obstetric variation, intervention, and outcomes: Doing more but accomplishing less. Birth: Issues in Perinatal Care, 39, 286-90.

Greenhalgh, T. (2014). Evidence based medicine: A movement in crisis? British Medical Journal, 348, 1-7.

Griffiths, R. (2009). Maternity care pathways and the law. British journal of midwifery. British Journal of Midwifery, 17(5), 324-325.

Holton, L., \& de Miranda, E. (2016). Women’s motivations for having unassisted childbirth or high-risk homebirth: An exploration of the literature on 'birthing outside the system'. Midwifery, 38, 55-62.

Hunter, B. (2004). Conflicting ideologies as a source of emotion work in midwifery. Midwifery, 20(3), 261-272. 
International Confederation of Midwives. (2014). ICM international definition of a midwife. Retrieved from http://www.internationalmidwives.org/who-we-are/policyand-practice/icm-international-definition-of-the-midwife/

Jackson, M., Dahlen, H., \& Schmeid, V. (2012). Birthing outside of the system; perceptions of risk amongst Australian women who have freebirths and high pisk homebirths. Midwifery, 28, 561-567.

Jankowski, J., \& Burcher, P. (2015). Home birth of infants with congenital anomalies: A case study and ethical analysis of care providers' obligations. The Journal of Clinical Ethics, 26(1), 27-35.

Jenkinson, B., Kruske, S., \& Kildea, S. (2017). The experiences of women, midwives and obstetricians when women decline recommended maternity care: A feminist thematic analysis. Midwifery, 52, 1-10.

Jenkinson, B., Kruske, S., Stapleton, H., Beckmann, M., Reynolds, M., \& Kildea, S. (2015). Maternity care plans: A retrospective review of a process aiming to support women who decline standard care. Women and Birth: Journal of the Australian College of Midwives, 28(4), 303-309. doi:10.1016/j.wombi.2015.05.003

Jenkinson, B., Kruske, S., Stapleton, H., Beckmann, M., Reynolds, M., \& Kildea, S. (2016). Women's, midwives' and obstetricians' experiences of a structured process to document refusal of recommended maternity care. Women and Birth: Journal of the Australian College of Midwives, doi:10.1016/j.wombi.2016.05.005 
Karlström, A., Engström-Olofsson, R., Nysted, A., \& Thomas, J. H., I. (2009). Swedish caregivers' attitudes towards caesarean section on maternal request. Women and Birth, 22(2), 57-63.

Keedle, H., Schmeid, V., Burns, E., \& Dahlen, H. (2015). Women's reasons for, and experiences of, choosing a homebirth following a caesarean. BMC Pregnancy and Childbirth, 15(206)

Kotaska, A. (2011). Guideline-centered care: A two-edged sword. Birth: Issues in Perinatal Care, 38(2), 97-98.

Kotaska, A. (2017). Informed consent and refusal in obstetrics: A practical ethical guide. Birth: Issues in Perinatal Care, oo, 1-5.

Kruske, S., Young, K., Jenkinson, B., \& Catchlove, A. (2013). Maternity care providers' perceptions of women's autonomy and the law. BMC Pregnancy and Childbirth, 13, 8484. doi:10.1186/1471-2393-13-84

Lincoln, Y., \& Guba, E. (1985). Naturalistic inquiry. Newbury Park: Sage Publications. McKenna, J., \& Symon, A. (2014). Water VBAC: Exploring a new frontier for women's autonomy. Midwifery, 30, e2o-e25.

Noblit, G., \& Hare, R. (1988). Meta-ethnography: Synthesising qualitative studies. London:Sage.

Pollard, K. (2011). How midwives' discursive practices contribute to the maintenance of the status quo in English maternity care. Midwifery, 27(5), 612-619. 
Renfrew, M., McFadden, A., Bastos, M., Campbell, J., Channon, A., Cheung, N., Declercq, E. (2014). Midwifery and quality care: Findings from a new evidenceinformed framework for maternal and newborn care. The Lancet, 384(9948), 1129-1145. Sandall, J., Bourgeault, I., Meiger, W., \& Schuecking, B. (2001). Deciding who cares: The winners and losers in the late twentieth century. In R. De Vries, C. Benoit, E. van Teijlingen \& S. Wrede (Eds.), Birth by design: Pregnancy, maternity care and midwifery in north America and Europe (1st ed., pp. 117-138). New York: Routledge. Sandelowski, M., Docherty, S., \& Emden, C. (1996). Qualitative metasynthesis: Issues and techniques. Research in Nursing and Health, 20, 365-371.

Schutz, A. (1962). Collected papers (Vol 1 ed.). The Hague: Martinus Nijhoff. Sellar, M. (2008). Up front. the VBAC waterbirth experience in fife. Midwives, 11(4), 1819.

Shallow, H. (2013). Deviant mothers and midwives: Supporting VBAC with women as real partners in decision making. Essentially MIDIRS, 4(1), 17-21.

Symon, A. (2006). The risk-choice paradox. In A. Symon (Ed.), Risk and choice in maternity care. an international perspective. (pp. 1-3). Philadelphia: Elsevier.

Symon, A., Winter, C., Donnan, P., \& Kirkham, M. (2010). Examining autonomy’s boundaries: A follow-up review of perinatal mortality cases in UK independent midwifery. Birth, 37(4), 280-287.

The White Ribbon Alliance. (2013). 5 approaches to respectful maternity care. Retrieved from http://whiteribbonalliance.org/wp-content/uploads/2013/05/5Approaches-to-RMC.pdf 
Thomas, J., \& Harden, A. (2008). Methods for the thematic synthesis of qualitative research in systematic reviews. BMC Health Services Research, 8(45), 28th November 2014 .

Thompson. (2003). The practice setting: Site of ethical conflict for some mothers and midwives. Nursing Ethics, 10(6), 588-601.

Thompson. (2013). Midwives' experiences of caring for women whose requests are not within clinical policies and guidelines. British Journal of Midwifery, 21(8), 564-570.

Tong, A., Flemming, K., McInnes, E., Oliver, S., \& Craig, J. (2012). Enhancing transparency in reporting the synthesis of qualitative research. ENTREQ. BMC Medical Research Methodology, 12(181)

Upshur, R. (2014). Do clinical guidelines still make sense? no. Annals of Family Medicine, 12(3), 202-203.

Viisainen, K. (2000). The moral dangers of homebirth: Parents perception of risks in homebirth in Finland. Sociology of Health and Illness, 6, 792-814.

Walsh, D., \& Downe, S. (2006). Appraising the quality of qualitative research.

Midwifery, 22, 108-119.

Weisz, G., Cambrosio, A., Keating, P., Knappen, S., Schlich, T., \& Tournay, V. (2007). The emergence of clinical practice guidelines. Milbank Quarterly, 85(4), 691-727. doi:10.1111/j.1468-0009.2007.00505.X

Wickham, S. (2009). Post-term pregnancy: The problem of the boundaries. MIDIRS Midwifery Digest, 19(4), 463-469. 
Wickham, S. (2010). Journeying with women: Holistic midwives and relationships. Birthspirit Midwifery Journal, 6, 15-21.

Wickham, S. (2011). Stretching the fabric: From technocratic normal limits to holistic midwives' negotiations of normalcy. Essentially MIDIRS, 2(11), 17-23.

World Health Organisation. (2012). Respectful maternity care: The universal rights of childbearing women. Washington: White Ribbon Alliance. 


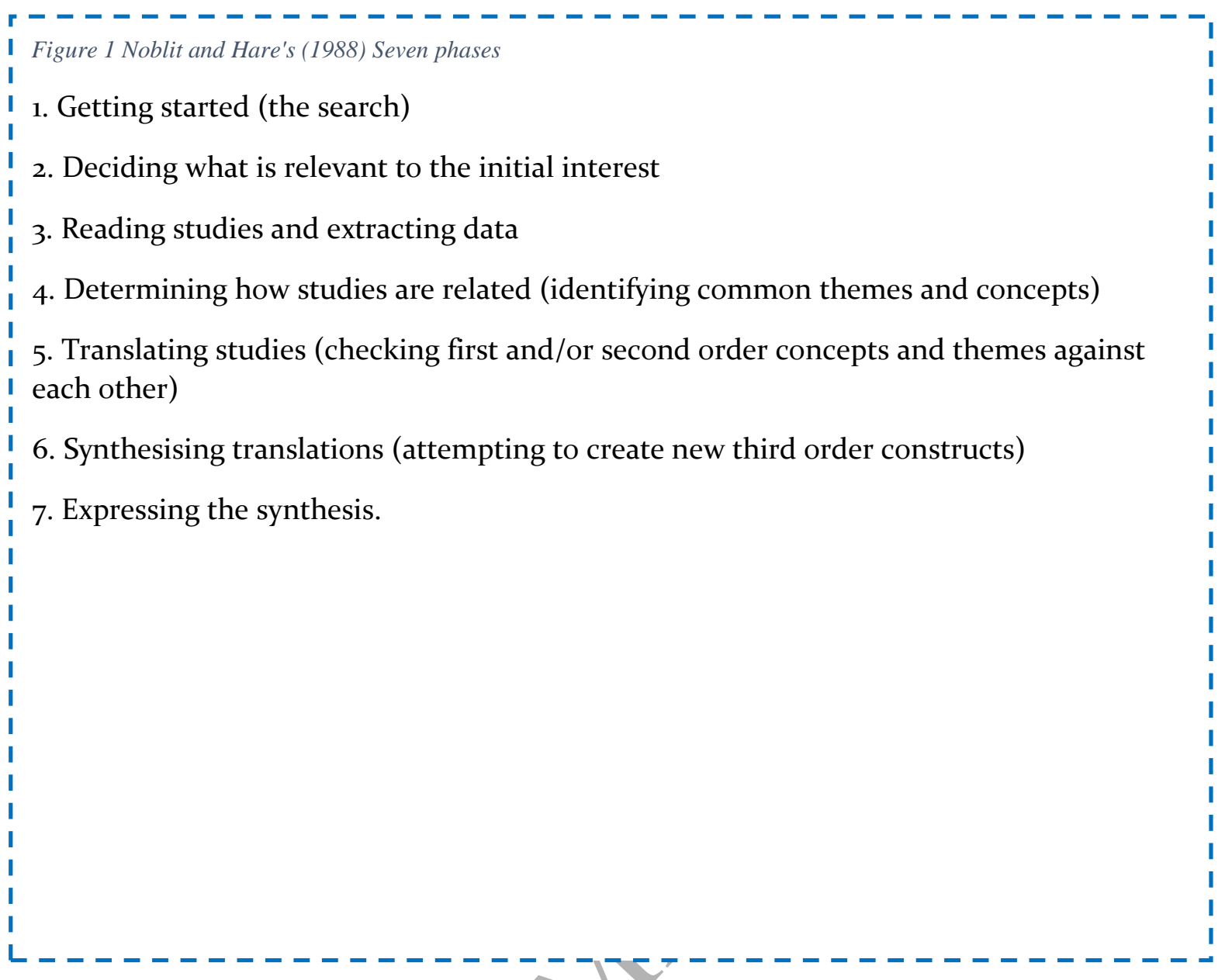




\begin{tabular}{|c|c|c|}
\hline & Inclusion & Exclusion \\
\hline Time frame & 1993 onwards & Pre 1993 \\
\hline Language & $\begin{array}{l}\text { English } \\
\text { Those that can be translated } \\
\text { with software }\end{array}$ & $\begin{array}{l}\text { Those that cannot be translated } \\
\text { with software }\end{array}$ \\
\hline Publications & $\begin{array}{l}\text { 1. Primary studies } \\
\text { 2. Grey literature that } \\
\text { involves primary research }\end{array}$ & $\begin{array}{l}\text { 1. Secondary sources } \\
\text { 2. Grey literature such as } \\
\text { opinion pieces, commentaries. }\end{array}$ \\
\hline Focus of paper & $\begin{array}{l}\text { The views, experiences, and } \\
\text { attitudes of qualified } \\
\text { midwives supporting or } \\
\text { facilitating women's } \\
\text { unconventional birth } \\
\text { choices. }\end{array}$ & $\begin{array}{l}\text { 1.The views, attitudes, and } \\
\text { experiences of women who } \\
\text { choose unconventional birth } \\
\text { choices. } \\
\text { 2.The views, attitudes, and } \\
\text { experiences of other maternity } \\
\text { professionals in relation to } \\
\text { unconventional birth. } \\
\text { 3.The views, attitudes, and } \\
\text { experiences of maternity } \\
\text { professionals in relation to } \\
\text { conventional birth choices. }\end{array}$ \\
\hline Methodology & $\begin{array}{l}\text { 1. Qualitative } \\
\text { 2. Mixed methods (e.g. } \\
\text { surveys) that include } \\
\text { qualitative component }\end{array}$ & $\begin{array}{l}\text { 1. RCT } \\
\text { 2. Quasi-experiments }\end{array}$ \\
\hline
\end{tabular}


Figure 2 PRSIMA diagram of search results
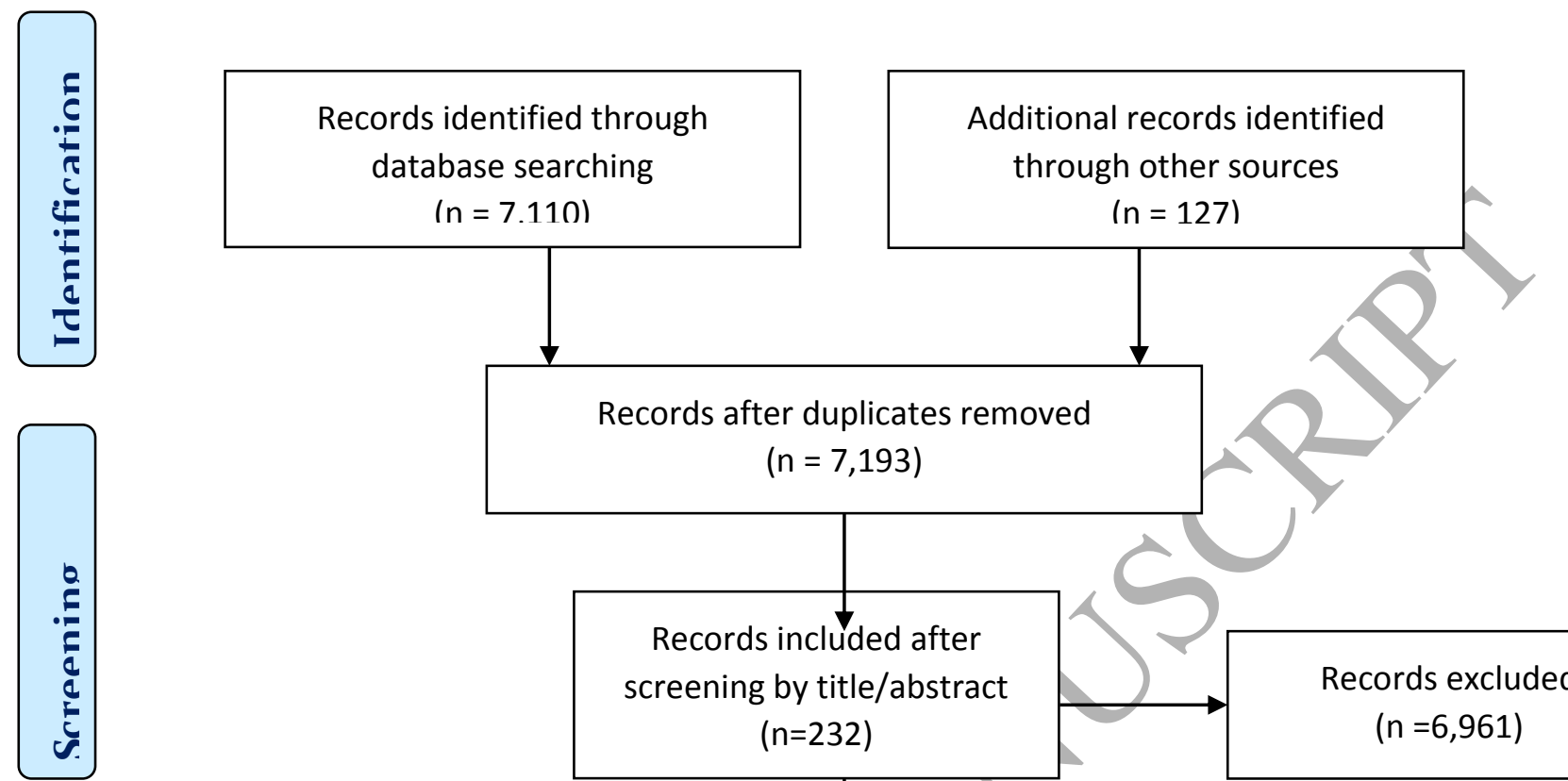

$(n=7,193)$

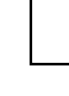
screening by title/abstract $(n=232)$

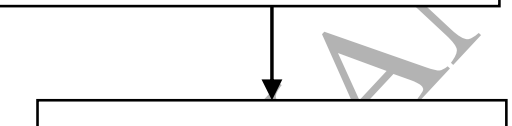

Full-text articles assessed for eligibility $(n=12)$

Studies included in qualitative synthesis $(n=5)$

Records excluded $(n=6,961)$

Full-text articles excluded, with reasons

$$
(n=5 \text { i.e. }
$$

$\mathrm{N}=1$ out of criteria $\mathrm{n}=2$ quantitative studies $\mathrm{n}=1$ case study

i.e. Articles included in qualitative synthesis

$$
(n=7)
$$

However, three included articles were from one study, therefore the number of studies included into the review $(n=5)$ 
Table 2 Study characteristics

\begin{tabular}{|c|c|c|c|c|c|c|c|c|}
\hline \multicolumn{3}{|c|}{ Study: } & \multicolumn{3}{|c|}{ Study Design: } & \multicolumn{2}{|r|}{ Findings } & \multirow[b]{2}{*}{$\begin{array}{c}\text { Qualit) } \\
\text { grade }\end{array}$} \\
\hline Code & $\begin{array}{l}\text { Author } \\
\text { Country }\end{array}$ & Aim & $\begin{array}{l}\text { Theoretical perspective/ } \\
\text { Methodology }\end{array}$ & $\begin{array}{c}\text { Sample } \\
\text { Setting } \\
\text { Data collection }\end{array}$ & Data analysis & $\begin{array}{c}\text { Ethics } \\
\text { Reflexivity }\end{array}$ & Key concepts & \\
\hline 1 & $\begin{array}{l}\text { Wickham } \\
\text { UK }\end{array}$ & $\begin{array}{l}\text { To explore the views and } \\
\text { knowledge of holistic } \\
\text { midwives in relation to } \\
\text { the obstetric construct of } \\
\text { post-term pregnancy }\end{array}$ & $\begin{array}{l}\text { Qualitative- } \\
\text { Grounded theory }\end{array}$ & $\begin{array}{l}\mathrm{n}=12 \text { 'holistic' } \\
\text { midwives } \\
\text { International setting } \\
\text { across } 5 \text { countries } \\
\text { Interviews }\end{array}$ & $\begin{array}{l}\text { Grounded theory, } \\
\text { comparative } \\
\text { analysis, theoretica } \\
\text { sampling until } \\
\text { saturation }\end{array}$ & $\begin{array}{l}\text { Ethical approval } \\
\text { granted } \\
\begin{array}{l}\text { No reflexivity } \\
\text { discussed }\end{array}\end{array}$ & $\begin{array}{l}\text { Core concept 'obstetric spacetime' } \\
\text { reflects the midwives perceptions of the } \\
\text { obstetric construct of post-term } \\
\text { pregnancy, therefore the findings } \\
\text { across three papers: 'boundaries', } \\
\text { 'journeying' and 'stretching the fabric' } \\
\text { depict their practice in relation to the } \\
\text { core concept. }\end{array}$ & $\bar{B}$ \\
\hline 2 & $\begin{array}{l}\text { Symon et al. } \\
\text { UK }\end{array}$ & $\begin{array}{l}\text { To examine independent } \\
\text { midwives management } \\
\text { and decision making in } 15 \\
\text { instances of perinatal } \\
\text { death at term }\end{array}$ & Qualitative- Descriptive & $\begin{array}{l}\mathrm{n}=15 \text { Independent } \\
\text { Midwives } \\
\text { Across UK } \\
\text { Interviews, case no } \\
\text { and member check }\end{array}$ & $\begin{array}{l}\text { Thematic analysis/ } \\
\text { grounded/Voice } \\
\text { Centred Relational } \\
\text { Method }\end{array}$ & $\begin{array}{l}\text { Ethical approval } \\
\text { granted } \\
\text { No reflexivity } \\
\text { discussed }\end{array}$ & $\begin{array}{l}\text { Homebirth was attempted in 13/15 } \\
\text { cases, all of which significant } \\
\text { (sometimes multiple) risk factors were } \\
\text { present. Women had declined aspects } \\
\text { of NHS care i.e. screening and/or } \\
\text { transfer to obstetric care. Care } \\
\text { management by the Independent } \\
\text { Midwives was acceptable within the } \\
\text { parameters set by the mother's choices. }\end{array}$ & B \\
\hline 3 & $\begin{array}{l}\text { Thompson } \\
\text { UK }\end{array}$ & $\begin{array}{l}\text { To explore midwives' } \\
\text { experiences of caring for } \\
\text { women who make } \\
\text { choices outside of } \\
\text { guidelines }\end{array}$ & Qualitative & tting in one & Thematic analysis & $\begin{array}{l}\text { Ethics approval } \\
\text { granted } \\
\text { Some reflexivity }\end{array}$ & $\begin{array}{l}\text { Four key themes: } 1 \text {. Effects on care and } \\
\text { concerns; } 2 \text {. Coping strategies and } \\
\text { getting on; } 3 \text {. Women's characteristics; } \\
\text { 4. Influence of others. }\end{array}$ & $\bar{C}$ \\
\hline 4 & $\begin{array}{l}\text { Cobell } \\
\text { UK }\end{array}$ & $\begin{array}{l}\text { To gain an understanding } \\
\text { of midwives' experiences } \\
\text { of looking after women in } \\
\text { labour outside of Trust } \\
\text { guidelines }\end{array}$ & $\begin{array}{l}\text { Qualitative- Interpretative } \\
\text { Phenomenologieal Analysis } \\
\text { (IPA) }\end{array}$ & $\begin{array}{l}\mathrm{n}=6 \text { midwives } \\
\text { Hospital setting in one } \\
\text { Trust } \\
\text { Interviews }\end{array}$ & IPA & $\begin{array}{l}\text { Ethics approval } \\
\text { granted } \\
\text { Some reflexivity } \\
\text { present }\end{array}$ & $\begin{array}{l}\text { Four superordinate themes: } 1 \text {. Women } \\
\text { requesting alternative care; } 2 \text {. Being the } \\
\text { professional; } 3 \text {. The concerns regarding } \\
\text { care outside of guidelines; } 4 \text {. Strategies } \\
\text { to enable out with guidelines care to } \\
\text { continue. }\end{array}$ & $\bar{C}$ \\
\hline 5 & $\begin{array}{l}\text { Jenkinson et al. } \\
\text { Australia }\end{array}$ & $\begin{array}{l}\text { To document the } \\
\text { perspectives of women, } \\
\text { midwives and } \\
\text { obstetricians following } \\
\text { the introduction of a } \\
\text { structured process to } \\
\text { document refusal of } \\
\text { recommended maternity } \\
\text { care. }\end{array}$ & & $\begin{array}{l}\begin{array}{l}\mathrm{N}=9 \text { women, } \mathrm{N}=12 \\
\text { midwives, } \mathrm{N}=9 \\
\text { obstetricians }\end{array} \\
\begin{array}{l}\text { Hospital setting in one } \\
\text { tertiary hospital }\end{array} \\
\text { Interviews }\end{array}$ & Thematic analysis & $\begin{array}{l}\text { Ethics approval } \\
\text { granted } \\
\text { No reflexivity } \\
\text { discussed }\end{array}$ & $\begin{array}{l}\text { Four key themes: 1. Reassuring and } \\
\text { supporting clinicians; } 2 \text {. Keeping the } \\
\text { door open; } 3 \text {. Varied awareness, criteria } \\
\text { and use of the MCP process; } 4 \text {. No } \\
\text { guarantees }\end{array}$ & B \\
\hline
\end{tabular}


Table $31^{\text {st }} / 2^{\text {nd }} / 3^{\text {rd }}$ order constructs with study code numbers

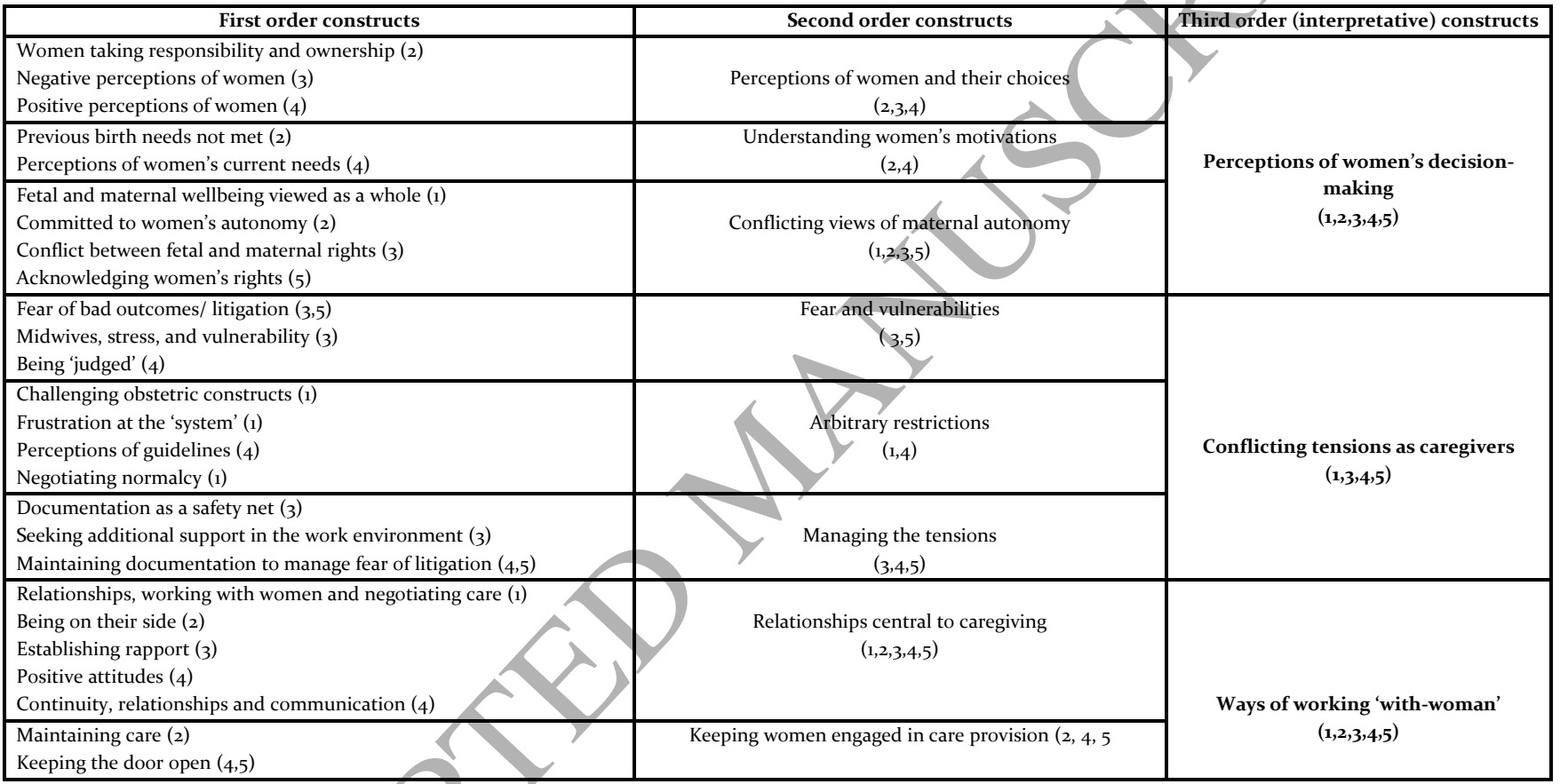

